\title{
Coronary metabolic adaptation restricted by endothelin in the dog heart
}

\author{
L. Fazekas ${ }^{1}$, Violetta Kékesi ${ }^{1}$, P. Soós ${ }^{1}$, Erzsébet Barát ${ }^{2}$, \\ Éva Huszár ${ }^{2}$, A. Juhász-Nagy ${ }^{1}$ \\ ${ }^{1}$ Department of Cardiovascular Surgery, Semmelweis University, Budapest, Hungary \\ ${ }^{2}$ National Korányi Institute for Pulmonology, Budapest, Hungary
}

Received: May 24, 2001

Accepted: July 20, 2001

\begin{abstract}
Endothelin elicits long-lasting vasoconstriction in the coronary bed. This remarkable spastic response raises the question whether or not the metabolic adaptive mechanisms of the coronaries are activated under endothelin effect. The role of the compensatory mediators adenosine and inosine was investigated before and after intracoronary (ic.) administration of endothelin-1 (ET-1, $1.0 \mathrm{nmol})$ using 1-min reactive hyperemia $(\mathrm{RH})$ tests on in situ dog hearts $(\mathrm{n}=15)$ with or without blocking the ATP-sensitive potassium $\left(\mathrm{K}^{+}{ }_{\text {ATP }}\right)$ channels by glibenclamide (GLIB, $1.0 \mu \mathrm{mol} \mathrm{min}{ }^{-1}$, ic.). The release of adenosine and inosine via the coronary sinus was measured by HPLC during the first minute of RH. Endothelin-1 reduced baseline coronary blood flow $(\mathrm{CBF})$ and $\mathrm{RH}$ response (hyperemic excess flow (EF) control vs. ET-1: $81.7 \pm 13.6$ vs. $43.4 \pm 10.9 \mathrm{ml}, \mathrm{P}<0.01$ ), while it increased the net nucleoside release (adenosine, control vs. ET-1: $58.9 \pm 20.4$ vs. $113.7 \pm 39.4 \mathrm{nmol}, \mathrm{P}<0.05$; inosine: $242.1 \pm 81.8$ vs. $786.9 \pm 190.8 \mathrm{nmol}, \mathrm{P}<0.05$ ). GLIB treatment alone did not change baseline CBF but also reduced RH significantly and increased nucleoside release (EF control vs. GLIB: $72.1 \pm 11.7$ vs. $31.9 \pm 5.5 \mathrm{ml}, \mathrm{P}<0.01$; adenosine: $18.8 \pm 4.6$ vs. $63.0 \pm 24.8 \mathrm{nmol}, \mathrm{P}<0.05$; inosine: $113.0 \pm 37.2$ vs. $328.2 \pm 127.5 \mathrm{nmol}, \mathrm{P}<0.05)$. Endothelin-1 on GLIB-treated coronaries further diminished RH and increased nucleoside release (EF: $21.5 \pm 8.0 \mathrm{ml}, \mathrm{P}<0.05$ vs. GLIB; adenosine: $75.3 \pm 28.1 \mathrm{nmol}, \mathrm{NS}$; inosine: $801.9 \pm 196.6 \mathrm{nmol}$, $\mathrm{P}<0.05$ vs. GLIB).
\end{abstract}

Correspondence should be addressed to

Professor A. Juhász-Nagy, M.D.

Experimental Research Laboratory

Dept. of Cardiovascular Surgery

Semmelweis University

H-1122 Budapest, Városmajor u. 68, Hungary

Phone/Fax: +36-1-355-46-84

E-mail: juhnagy@hermes.sote.hu

The work was supported by the Hungarian Scientific Research Fund (OTKA numbers T 16268, T 16270, and T 29677). 
The data show that ET-1 reduces metabolic adaptive capacity of the coronaries, and this phenomenon is due to decreased vascular responsiveness and not to the blockade of ischemic mediator release from the myocardium. The coronary effect of ET-1 may partially be dependent on $\mathrm{K}^{+}{ }_{\text {ATP }}$ channels.

Keywords: adenosine, inosine, glibenclamide, $\mathrm{K}^{+}$ATP channels, reactive hyperemia, coronary metabolic adaptation

Transient reduction or interruption of coronary blood flow (CBF) is followed by the release of metabolites such as adenosine and inosine from myocardial cells. After cessation of the occlusion these metabolites dilate the coronary arteries to adjust CBF to increased myocardial $\mathrm{O}_{2}$ demands. A similar compensatory $\mathrm{CBF}$ increase is missing following endothelin-induced spasm: endothelin-1 (ET-1) which is the most potent vasoconstrictor known so far (33) exerts a long-lasting CBF decrease without any signs of secondary vasodilation, i.e. without a restitution phenomenon (16). The question emerges which mechanisms could be responsible for this unusual spastic effect, whether it is related to an altered myocardial adenine nucleoside production, and whether the ATP-sensitive potassium $\left(\mathrm{K}^{+}\right.$ATP $)$membrane channels are involved in it.

In 1983 Noma (24) discovered the presence of $\mathrm{K}^{+}{ }_{\text {ATP }}$ channels in cardiac muscle and Daut et al. (7) have shown their significance in the control of coronary circulation. The blockade of these channels simultaneously antagonizes both metabolic adaptive responses $(2,6,10)$ and adenine nucleoside-induced vasodilation $(1,4,6,10,15)$ in the coronary bed. To investigate the role of endogenous adenosine and its first degradation product inosine in the compensation of ET-1 induced changes in vascular reactivity, the release of adenine nucleosides into the coronary sinus was measured utilizing reactive hyperemia $(\mathrm{RH})$ tests before and after intracoronary (ic.) ET-1 administration, and after ic. pretreatment with the $\mathrm{K}^{+}{ }_{\text {ATP }}$ blocker glibenclamide (GLIB).

\section{Methods}

\section{General preparation}

All experiments were done in accordance with the Guide for Care and Use of Laboratory Animals published by the United States National Institutes of Health (NIH publication No. 85-23, revised 1985). Adult, healthy mongrel dogs $(n=15)$ weighing $22.1 \pm 4.8 \mathrm{~kg}$ were anesthetized with intravenous pentobarbital sodium $\left(30 \mathrm{mg} \mathrm{kg}^{-1}\right)$. The animals were intubated, ventilated with room air, and the chest was opened by a transverse thoracotomy in the fifth intercostal space. The left anterior descending (LAD) coronary artery was dissected free and an ultrasonic flow probe (Transonic Systems Inc.) was placed around the vessel. A thin bent-tip butterfly needle (23-gauge) was 
inserted into LAD for drug administration. After administering 5000 IU Heparin iv., the coronary sinus (CS) was cannulated through the azygos vein and an extracorporeal shunt was created between the CS and the right external jugular vein. A Y-connector was used for CS blood sampling. Systemic blood pressure was monitored in the femoral artery. All hemodynamic data were recorded on personal computer.

\section{Experimental protocol}

In the first set of experiments $(\mathrm{n}=8)$ after hemodynamic stabilization, CS and arterial blood samples were taken to determine baseline nucleoside concentrations. Hemodynamic parameters were measured and the RH test was performed with 1-min LAD occlusion. By using the 1-min occlusion time, maximal postischemic vasodilation can be obtained at the height of hyperemia (10). Immediately after the release of occlusion fractional blood samples were collected from CS for a duration of 1-min at 10 -sec intervals. After the elapse of a 20-min recovery period ic. bolus injection of ET-1 ( $1.0 \mathrm{nmol}$ in $0.2 \mathrm{ml}$ saline) was administered. Five to ten-min after ET-1 administration a second RH test combined with fractional blood sampling was performed similarly to the control phase.

In the second set of experiments $(n=7)$ following control RH the coronary metabolic adaptive capacity was blocked by ic. GLIB infusion $\left(1.0 \mu \mathrm{mol} \mathrm{min}^{-1}\right)$. After a repeated RH test the effects of ET-1 on RH was studied on GLIB treated coronary vessels. In the course of all RH tests coronary sinus and arterial blood samples were taken as described in the first experimental setup.

Endothelin-1 was purchased from SIGMA, and glibenclamide from RBI Inc.

\section{Biochemical analysis}

From the CS and the femoral artery $4.5 \mathrm{~mL}$ blood was taken with a syringe containing $1.5 \mathrm{ml}$ of ice-cold stop solution to inhibit adenosine degradation and inosine formation. The stop solution contained $400 \mu \mathrm{M}$ dipyridamole and $10 \mu \mathrm{M}$ erythro-9(2hydroxy-3-nonyl)-adenine (EHNA) dissolved in saline. The samples were centrifuged at $4{ }^{\circ} \mathrm{C}$ with $1000 \mathrm{~g}$ for 20 -min and stored at $-20{ }^{\circ} \mathrm{C}$ until biochemical analysis. The adenosine and inosine contents of samples were determined by HPLC with UV detection. Details of the method have been previously reported (14). 


\section{Experimental variables}

Systemic blood pressure and blood flow in the LAD were presented as electronically integrated mean values. Heart rate was calculated from blood pressure tracings. Metabolic adaptive capacity of the coronary vessels was characterized by reactive hyperemic excess flow (EF), i.e. the time-integrated volume flow in excess above the pre-occlusion baseline (10). Integration of volume flow was performed by means of an off-line computer program. Adenine nucleoside output was characterized by the net release of these agents via the CS (arteriovenosus concentration difference times flow) during the first minute of RH. In order to characterize the relation of blood flow to myocardial nucleoside production, the actual level of mean CBF was plotted against the logarithmic value of the respective adenosine and inosine output in 10-sec time slices during the reactive hyperemic response.

\section{Statistical analysis}

Analysis of variance for repeated measurements with Scheffe's contrasts was performed for multiple comparisons. As biochemical data did not follow normal distribution, Wilcoxon Signed Ranks test and logarithmic transformation was used for data analysis. Results are expressed as mean \pm SEM. Probability values less than 0.05 were considered significant.

\section{Results}

In the first series of experiments ic. administration of ET-1 in a single dose of $1.0 \mathrm{nmol}$ significantly reduced both $\mathrm{CBF}$ and $\mathrm{RH}$ as compared to control values. These hemodynamic changes of the ET-1 induced lasting coronary vasoconstriction were associated with a considerable potentiation of adenosine and inosine release from the myocardium through the coronary sinus during the first minute of post-occlusion hyperemia (Table I). The enhanced release of adenine nucleosides with the simultaneous reduction of RH response after ET-1 resulted in a shift in both adenosineto-CBF and inosine-to-CBF regression lines (Fig. 1). 


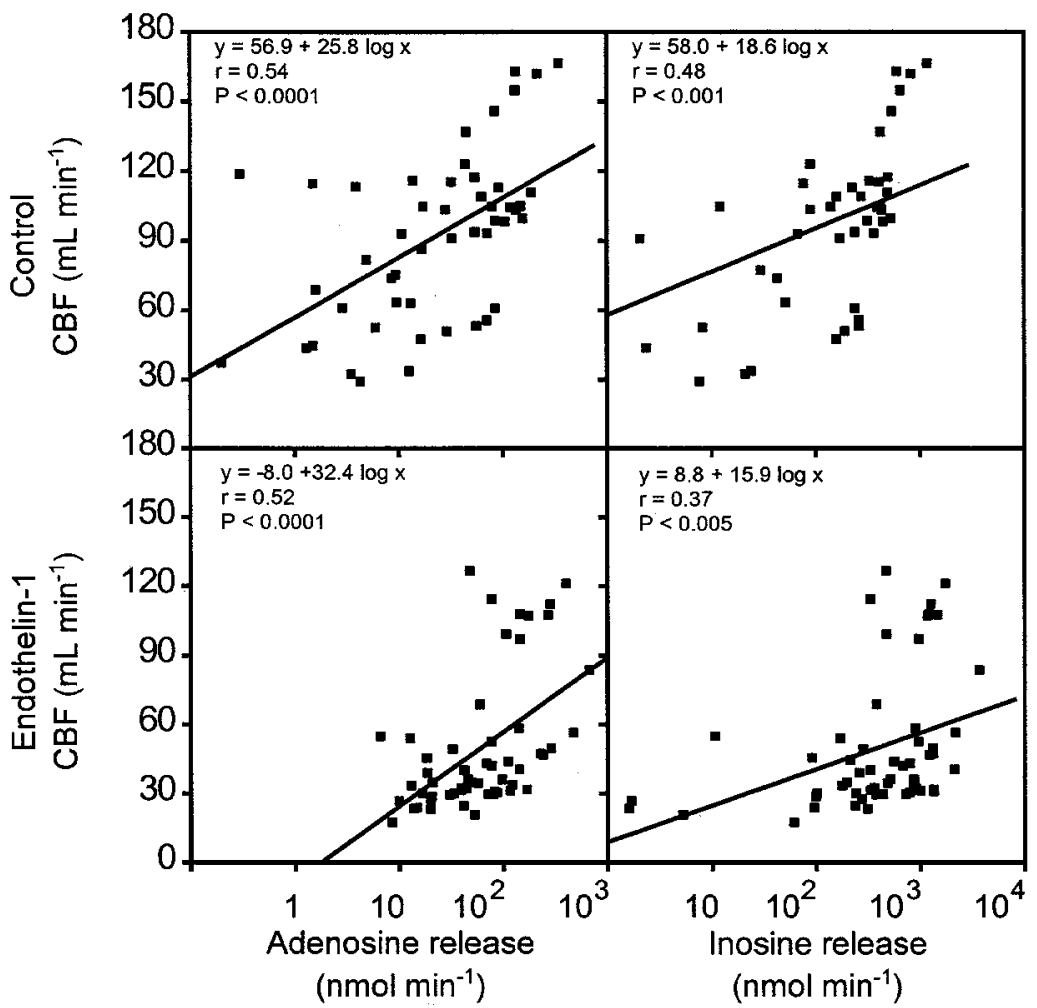

Fig. 1. Correlation between reactive hyperemic flow (CBF) and adenosine/inosine release before and after ET-1 treatment. Mean CBF was correlated with the respective output of adenine nucleosides in 10-sec timeslices during RH tests in each experiment. Note that the released amounts of adenosine and inosine are shown on logarithmic scales

In the second series of experiments the $\mathrm{K}^{+}{ }_{\text {ATP }}$ channels were blocked by continuous infusion of GLIB $\left(1 \mu \mathrm{mol} \mathrm{min}^{-1}\right)$ into the LAD artery. The representative diagrams of Figure 2 depict the characteristic hemodynamic changes, while Table II summarizes the main results of all experiments. GLIB infusion did not modify baseline CBF. However, it reduced the RH response significantly and increased the net adenine nucleoside release during the first min of the RH test. On GLIB-treated coronaries ET-1 decreased $\mathrm{CBF}$ and further reduced $\mathrm{RH}$, whereas the net adenine nucleoside release increased. The shifts in adenosine-to-CBF and inosine-to-CBF lines, resulting from the increase in nucleoside release and the concomitant decrease of reactive hyperemic coronary flow during $\mathrm{K}^{+}{ }_{\text {ATP }}$ blockade and after the subsequent ET-1 treatment, are shown in Fig. 3. 


\section{Table I}

Effects of ET-1 on hemodynamics and nucleoside release

\begin{tabular}{lcc}
\hline \multicolumn{1}{c}{$(\mathrm{n}=8)$} & Control & ET-1 \\
\hline Baseline CBF $\left(\mathrm{ml} \mathrm{min}^{-1}\right)$ & $39.2 \pm 4.3$ & $27.8 \pm 4.1 \ddagger$ \\
$\mathrm{EF}(\mathrm{ml})$ & $81.7 \pm 13.6$ & $43.4 \pm 10.9 \ddagger$ \\
$\mathrm{BP}(\mathrm{mm} \mathrm{Hg})$ & $94.4 \pm 4.8$ & $92.2 \pm 4.2$ \\
$\mathrm{HR}($ beat min & -1 & $142.2 \pm 2.9$ \\
Adenosine* $(\mathrm{nmol})$ & $145.6 \pm 8.2$ & $113.7 \pm 39.4$ \\
Inosine* $\left.^{-\mathrm{nmol}}\right)$ & $58.9 \pm 20.4$ & $786.9 \pm 190.8 \dagger$ \\
\hline
\end{tabular}

CBF - coronary blood flow;

$\mathrm{EF}$ - hyperemic excess flow;

$\mathrm{BP}$ - blood pressure;

HR - heart rate;

* Net nucleoside release during the first minute of reactive hyperemia after 1-min occlusion; $\ddagger \mathrm{P}<0.01$ vs. Control; $\uparrow \mathrm{P}<0.05$ vs. Control. Values are means \pm SEM.

\section{Table II}

Effects of ET-1 after GLIB Pre-treatment on hemodynamics and nucleoside release

\begin{tabular}{|c|c|c|c|}
\hline$(n=7)$ & Control & GLIB & ET-1 \\
\hline Baseline CBF $(\mathrm{ml} \mathrm{min}-1)$ & $29.4 \pm 1.9$ & $26.0 \pm 2.4$ & $19.0 \pm 2.0 \ddagger \S$ \\
\hline $\mathrm{EF}(\mathrm{ml})$ & $72.1 \pm 11.7$ & $31.9 \pm 5.5 \ddagger$ & $21.5 \pm 8.0 \ddagger \S$ \\
\hline $\mathrm{BP}(\mathrm{mm} \mathrm{Hg})$ & $99.4 \pm 4.3$ & $100.0 \pm 3.2$ & $101.9 \pm 4.2$ \\
\hline HR (beat $\min ^{-1}$ ) & $151.3 \pm 4.1$ & $146.9 \pm 3.8$ & $143.1 \pm 4.9$ \\
\hline Adenosine* (nmol) & $18.8 \pm 4.6$ & $63.0 \pm 24.8 \dagger$ & $75.3 \pm 28.1 \dagger$ \\
\hline Inosine* $(\mathrm{nmol})$ & $113.0 \pm 37.2$ & $328.2 \pm 127.5 \dagger$ & $801.9 \pm 196.6 \dagger \S$ \\
\hline
\end{tabular}

$\mathrm{CBF}$ - coronary blood flow;

$\mathrm{EF}$ - hyperemic excess flow;

$\mathrm{BP}$ - blood pressure;

HR - heart rate;

*Net nucleoside release during the first minute of reactive hyperemia after 1 -min occlusion; $\neq \mathrm{P}<0.01$ vs.

Control; $\uparrow \mathrm{P}<0.05$ vs. Control; $\S \mathrm{P}<0.05$ vs. Glibenclamide. Values are means \pm SEM. 


\section{Discussion}

In agreement with preliminary results obtained in the dog heart (11), the present investigation shows that a single dose of ET-1 is capable of significantly decreasing metabolic adaptive capacity in the coronary vascular bed, and, at the same time, of increasing release from the heart of metabolic mediators. The long-lasting coronary vasoconstriction following ET-1 administration, a major finding of these results (Tables I and II), also confirms a number of previous reports (for reference see $(16,26)$ ).

The hypothesis underlying the present experiments was that the uniquely strong and lasting coronary constrictor action of ET-1 could tentatively be explained, at least partly, by a powerful inhibition of metabolic stimuli dilating these vessels. The hypothesis was examined by simultaneously measuring the hemodynamic phenomenon of $\mathrm{RH}$ and the myocardial production of adenine nucleosides involved in the latter.
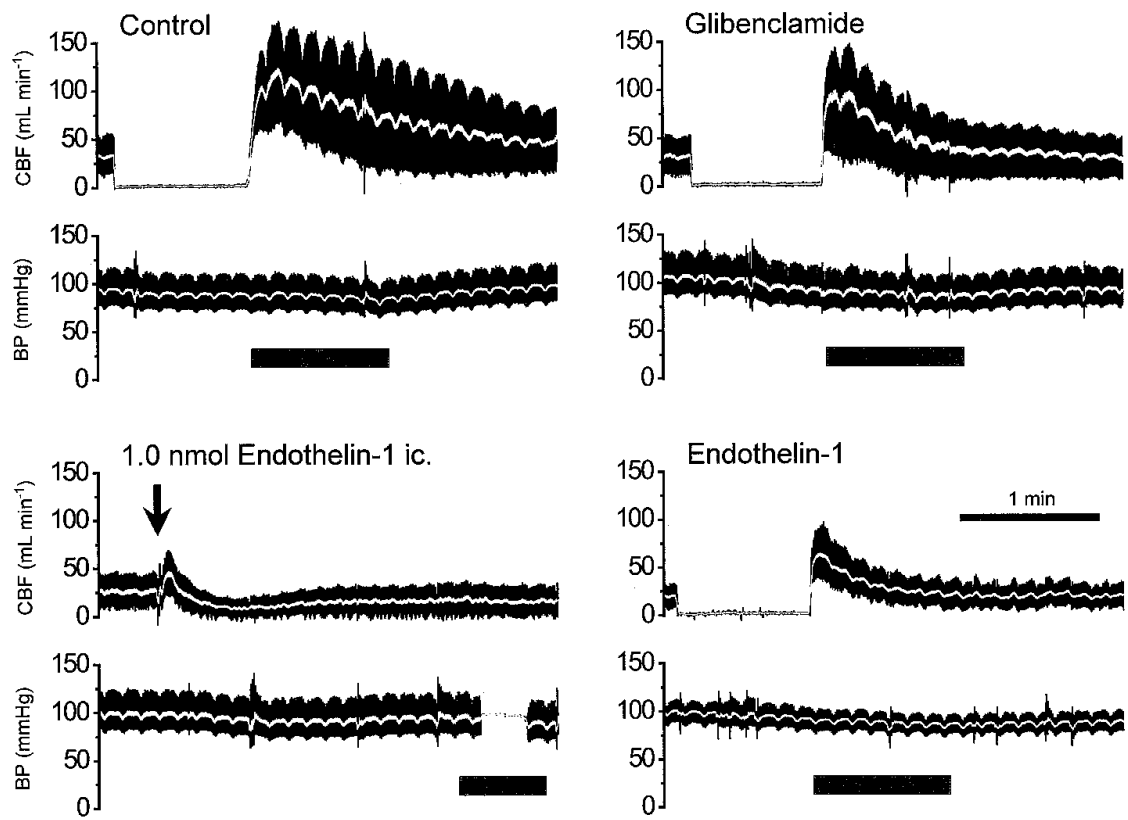

Fig. 2. Representative coronary blood flow (CBF) and blood pressure (BP) tracings (2nd set of experiments). Control indicates basal reactive hyperemic response on the LAD coronary artery with 1-min occlusion. Glibenclamide indicates hyperemic response during ic. infusion of GLIB $\left(1.0 \mu \mathrm{mol} \mathrm{min}{ }^{-1}\right)$, and Endothelin-1 indicates the hyperemic response 5-min after ic. ET-1 $(1.0 \mathrm{nmol})$. In the left lower panel the prompt vasoconstrictor action of ET-1 is shown. Striped boxes indicate blood samplings and white lines on all tracings indicate mean values 


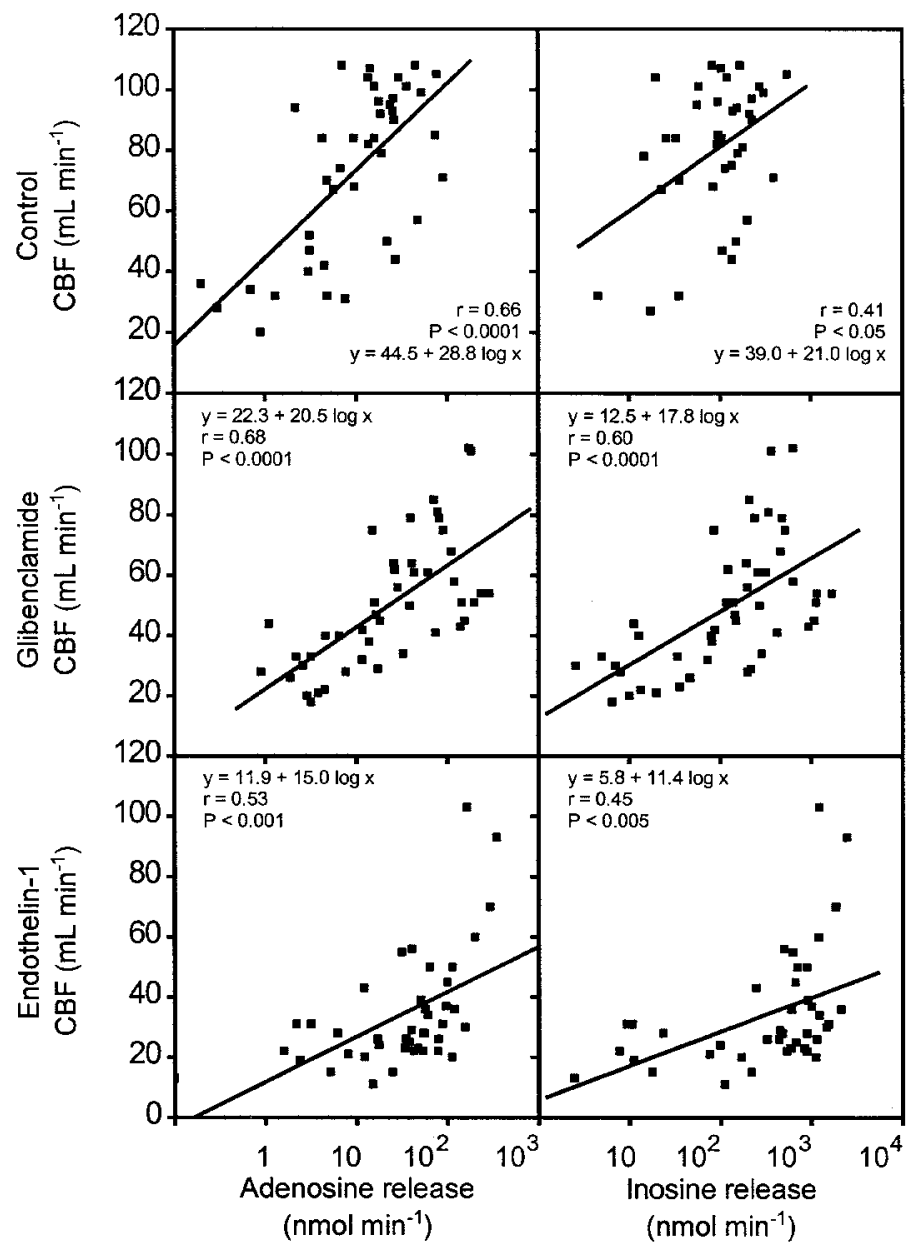

Fig. 3. Correlation between reactive hyperemic flow (CBF) and adenosine/inosine release before and after $\mathrm{K}_{\text {ATP }}^{+}$channel blockade (Glibenclamide) and subsequent ET-1 treatment. Signs as in Fig. 1

RH has repeatedly been shown to be a reproducible index of coronary metabolic capacity (12), which with experimental protocols similar to the present one remains remarkably stable over a considerable period of time (10). The occlusion time (1 min) used in this study was long enough to obtain near maximal peak hyperemic vasodilator responses $(10,12)$, but it was too short to elicit the phenomenon of preconditioning (31). At the same time, it should be noted that RH is not exclusively "chemically" mediated: the early overshoot of flow immediately after releasing occlusion is largely 
due to vascular myogenic responses $(8,12)$ elicited by reduced transmural pressure which is not metabolically determined. Moreover, transmitters other than adenine nucleosides may contribute to flow adjustments. Blood flow dependent endotheliumderived agents, especially $\mathrm{NO}$, apparently contribute to the $\mathrm{RH}$ in the coronaries, as they do in most vascular beds (20). Nevertheless, both the decisive role played by the adenine nucleosides and their relative chemical stability as compared to NO make these agents ideal markers of metabolic imbalance in flow control $(9,13,23)$. The present studies proved for the first time the enhanced release of adenosine and inosine from the myocardium on a provoked transitory ischemic stress after ET-1 administration. Because under basal conditions the adenine nucleoside output via the coronary venous drainage of the dog heart is very small [usually it is less than $2 \mathrm{nmol} \mathrm{min}^{-1}$ and $4 \mathrm{nmol} \mathrm{min}^{-1}$ for adenosine and inosine, respectively, (11)], for practical reasons a wellquantified reversible ischemic load (RH) was applied. By plotting hyperemic (postischemic) flow values against nucleoside release, the shift of regression lines appears to provide indirect evidence for the reduced potency under ET-1 influences of endogenous adenosine and inosine as coronary vasodilators. Consequently, the RH attenuating action of ET-1 can be ascribed to the decreased responsiveness of the coronaries to the nucleosides, and not to the blocked myocardial release of these metabolic mediators. In agreement with the present findings ET-1 was shown in earlier experiments to inhibit dose-dependently the acetycholine-induced coronary vasodilation $(16,30)$, which is mediated by NO release. In the dog heart the peptide was able to reduce this response significantly even in subthreshold doses (30), while the threshold dose of ET-1 reduced the maximal acetylcholine effect to about one-fifth value of control (16). Accordingly, a close parallelism exists between the coronary sensitivity to both important types of vasodilator mediators: adenine nucleosides and NO.

GLIB which effectively blocks $\mathrm{K}^{+}$ATP channels proved to be a useful pharmacological tool to elucidate further the mechanism of ET-1 action on the coronary vessels. The possible interaction between $\mathrm{K}^{+}{ }_{\text {ATP }}$ membrane channels and ET-1 was first proposed by Miyoshi et al. (22) who concluded that ET-1 specifically blocks $\mathrm{K}^{+}$ATP channels in cultured vascular muscle cells and the subsequent membrane depolarization results in contraction, mainly through an augmented intracellular $\left[\mathrm{Ca}^{2+}\right]$. This action may be additive to the augmented $\mathrm{Ca}^{2+}$-sensitivity of vascular contractile elements occurring under the influence of ET-1 (25). Later, Watanuki et al. (32) on isolated myocardial cells demonstrated a reversible inhibition of $\mathrm{K}^{+}{ }_{\text {ATP }}$ channels and suggested that this effect was mediated by the increase in subsarcolemmal ATP concentration consequent to adenylate cyclase inhibition in the subsarcolemmal "fuzzy space" (5). Although the latter supposition remains to be elucidated, the important hypotheses of Japanese workers are in line with a considerable number of investigations indicating the dependence of both coronary adaptive mechanisms and adenine nucleoside-induced 
coronary responses upon the activation of $\mathrm{K}^{+}{ }_{\text {ATP }}$ channels on one hand $(2,6,7,10,16$, 17), and upon the generation of cAMP from ATP, on the other $(3,19,27)$. Furthermore, blockers of $\mathrm{K}^{+}{ }_{\text {ATP }}$ channels such as GLIB dose-dependently reduce metabolic adaptive vasodilator mechanisms of the coronary vessels $(2,4,6,10)$. Based on these data the highest blocking GLIB concentration has recently been assessed by determining the maximal ic. dose that selectively inhibits both coronary adaptation and exogenous adenosine or inosine actions without any systemic effects (10). In the present study the same GLIB dose $\left(1 \mu \mathrm{mol} \mathrm{min}^{-1}\right)$ significantly reduced $\mathrm{RH}$ without changing basal CBF. This is consistent with Noma's original concept (24) of $\mathrm{K}^{+}$ATP channels not being operational in basal conditions and open only under a metabolic stress. However, in the GLIB-treated coronary bed the enhancement of RH-induced nucleoside release was similar in its proportion to that measured after ET-1 treatment. Subsequent administration of ET-1 into the GLIB-treated coronary circulation was able to accentuate both characteristic features of adaptation-shift during RH. Taken together, these results indicate a considerable overlap in the underlying mechanisms, suggesting that ET-1 and GLIB may share some common intracellular pathways in the inhibition of adaptive coronary vasodilation. On the other hand, the maintained capacity of ET-1 for eliciting coronary vasoconstriction after GLIB treatment and the simultaneous potentiation of nucleoside release indicated that the ET-1 actions could only partially be mediated via $\mathrm{K}^{+}{ }_{\mathrm{ATP}}$ channels.

In general, these findings may imply (but do not prove) some pathophysiologic actions of endogenous ET- 1 in the body. The alteration of the metabolic compensatory mechanisms by ET-1 is a notable aspect of the tentative endothelin-induced coronary vasospasm in humans $(18,20)$, and it may have significant relevance in ischemia/reperfusion injury caused by ET-1 after cardiac transplantation (23). These assumptions are closely related to the effective endogenous ET-1 level which is reportedly very low $(\leq 1.0 \mathrm{pmol} / \mathrm{l})$ in plasma (26). In the light of the latter fact the ET-1 dose used in this study might be considered pharmacological. However, acting from within the coronary vessels is only one way in which the peptide can influence vascular tone: paracrine effects are apparently more important and are poorly reflected in plasma levels. Recently, it was found that the pericardial fluid, which is a transsudate and thus may reflect the composition of the interstitial fluid contains nearly two orders higher concentrations of ET-1 than plasma (29). (In the dog heart the pericardial ET-1 level incidentally exceeds four hundred times the corresponding plasma level.) Possibly this is one of the bases of ET-1 induced arrhythmogenesis (29), a pathophysiological event analogous phenomenologically with the peptide-induced inhomogeneity of flow: neither of them could be explained without supposing self-maintained and/or amplified local actions. There are several other possibilities of homeostatic instability similar to the above-mentioned examples that need, however, further investigations. 


\section{Acknowledgement}

The authors gratefully remember the late Márta Rajczi (Mrs. Csongor) who performed, despite her fatal illness, excellent technical and secretarial work while doing these studies.

\section{REFERENCES}

1. Akatsuka, Y., Egashira, K., Katsuda, Y., Narishige, T., Ueno, H., Shimokawa, H., Takeshita, A.: ATP sensitive potassium channels are involved in adenosine $\mathrm{A}_{2}$ receptor mediated coronary vasodilatation in the dog. Cardiovasc. Res. 28, 906-911 (1994).

2. Aversano, T., Ouyang, P., Silverman, H.: Blockade of the ATP-sensitive potassium channel modulates reactive hyperemia in the canine coronary circulation. Circ. Res. 69, 618-622 (1991).

3. Belardinelli, L.: Adenosine system in the heart. Drug Dev. Res. 28, 263-267 (1993).

4. Belloni, F. L., Hintze, T. H.: Glibenclamide attenuates adenosine-induced bradycardia and coronary vasodilatation. Am. J. Physiol. 261, H720-H727 (1991).

5. Carmeliet, E.: A fuzzy subsarcolemmal space for intracellular $\mathrm{Na}^{+}$in cardiac cells? Cardiovasc. Res. 26, 433-442 (1992).

6. Clayton, F. C., Hess, T. A., Smith, M. A.: Coronary reactive hyperemia and adenosine-induced vasodilation are mediated partially by a glyburide-sensitive mechanism. Pharmacology 44, 92-100 (1992).

7. Daut, J., Maier-Rudolph, W., von-Beckerath, N., Mehrke, G., Gunther, K., Goedel-Meinen, L.: Hypoxic dilation of coronary arteries is mediated by ATP-sensitive potassium channels. Science $\mathbf{2 4 7}$ 1341-1344 (1990).

8. Eikens, E., Wilcken, D. E. L.: Myocardial reactive hyperemia and coronary vascular reactivity in the dog. Circ. Res. 33, 267-274 (1973).

9. Ely, S. W., Berne, R. M.: Protective effects of adenosine in myocardial ischemia. Circulation 85 , 893-904 (1992).

10. Fazekas, L., Soós, P., Fazekas, R., Kékesi, V., Juhász-Nagy, A.: Role of $\mathrm{K}^{+}{ }_{\text {ATP }}$ channels in the metabolic adaptation of the coronaries. Adv. Exp. Med. Biol. 471, 239-245 (1999).

11. Fazekas, L., Szabó, T., Barát, E., Huszár, É., Kékesi, V., Juhász-Nagy, A.: Compensation of endothelin-1-induced coronary vasoconstriction. J. Cardiovasc. Pharmacol. 31, S106-S108 (1998).

12. Feigl, E. O.: Coronary physiology. Physiol. Rev., 63, 1-205 (1983).

13. Hori, M., Kitakaze, M.: Adenosine, the heart, and coronary circulation. Hypertension 18, 565-574 (1991).

14. Huszár, É., Barát, E., Kollai, M.: Isocratic high-performance liquid chromatographic determination of plasma adenosine. Chromatographia 42, 318-322 (1996).

15. Juhász-Nagy, A., Kékesi, V., Fazekas, L.: Inosine-induced coronary vasodilation blocked by glibenclamide (abstract). J. Mol. Cell. Cardiol. 30, 137 (1998).

16. Juhász-Nagy, A., Kékesi, V., Fazekas, L., Merkely, B., Tóth, M.: Uneven flow distribution in the heart induced by endothelin. Adv. Exp. Med. Biol. 471, 247-256 (1999).

17. Kanatsuka, H., Sekiguchi, N., Sato, K., Akai, K., Wang, Y., Komaru, T., Ashikawa, K., Takishima, T.: Microvascular sites and mechanisms responsible for reactive hyperemia in the coronary circulation of the beating canine heart. Circ. Res. 71, 912-922 (1992).

18. Kaski, J. C., Elliott, P. M., Salomone, O., Dickinson, K., Gordon, D., Hann, C., Holt, D. W.: Concentration of circulating plasma endothelin in patients with angina and normal coronary angiograms. Br. Heart. J. 74, 620-624 (1995). 
19. Kleppisch, T., Nelson, M. T.: Adenosine activates ATP-sensitive potassium channels in arterial myocytes via $\mathrm{A}_{2}$ receptors and cAMP-dependent protein kinase. Proc. Natl. Acad. Sci. USA 92, 12441-12445 (1995).

20. Koller, Á., Kaley, G.: Shear stress dependent regulation of vascular resistance in health and disease: role of endothelium. Endothelium 4, 247-272 (1996).

21. Matsuyama, K., Yasue, H., Okumura, K., Saito, Y., Nakao, K., Shirakami, G., Imura, H.: Increased plasma level of endothelin-1-like immunoreactivity during coronary spasm in patients with coronary spastic angina. Am. J. Cardiol. 68, 991-995 (1991).

22. Miyoshi, Y., Nakaya, Y., Wakatsuki, T., Nakaya, S., Fujino, K., Saito, K., Inoue, I.: Endothelin blocks ATP-sensitive $\mathrm{K}^{+}$channels and depolarizes smooth muscle cells of porcine coronary artery. Circ. Res. 70, 612-616 (1992).

23. Mubagwa, K., Mullane, K., Flameng, W.: Role of adenosine in the heart and circulation. Cardiovasc. Res. 32, 797-813 (1996).

24. Noma, A.: ATP-regulated $\mathrm{K}^{+}$channels in cardiac muscle. Nature 305, 147-148 (1983).

25. Obara, K., Hata, S., Sato, K., Koide, M., Ishii, K., Nakayama, K.: Contractile potentiation by endothelin-1 involves protein kinase C- $\delta$ activity in the porcine coronary artery. Jpn. J. Physiol. 49, 175-183 (1999).

26. Rubányi, G. M., Polokoff, M. A.: Endothelins: molecular biology, biochemistry, pharmacology, physiology, and pathophysiology. Pharmacol. Rev. 46, 325-415 (1994).

27. Shryock, J. C., Belardinelli, L.: Adenosine and adenosine receptors in the cardiovascular system: biochemistry, physiology, and pharmacology. Am. J. Cardiol. 79(12A), 2-10 (1997).

28. Szabó, G., Fazekas, L., Bährle, S., MacDonald, D., Stumpf, N., Vahl, C. F., Hagl, S.: Endothelin-A and -B antagonists protect myocardial and endothelial function after ischemia/reperfusion in a rat heart transplantation model. Cardiovasc. Res. 39, 683-690 (1998).

29. Szokodi, I., Horkay, F., Merkely, B., Solti, F., Gellér, L., Kiss, P., Selmeci, L., Kékesi, V., Vuolteenaho, O., Leppäluoto, J., Ruskoaho, H., Juhász-Nagy, A., Tóth, M.: Intrapericardial infusion of endothelin-1 induces ventricular arrhythmias in dogs. Cardiovasc. Res. 38, 356-364 (1998).

30. Tóth, M., Kolossváry, E., Kékesi, V., Juhász-Nagy, A.: Subthreshold doses of endothelin attenuate the acetylcholine-induced coronary vasodilation in the dog (abstract). J. Vasc. Res. 29, 215 (1992).

31. Végh, Á., Parratt, J. R.: Ischaemic preconditioning markedly reduces the severity of ischaemia and reperfusion-induced arrhythmias; role of endogenous myocardial protective substances. In: Wainwright, C. L., Parratt, J. R. (eds): Myocardial Preconditioning, pp. 36-60. Springer Verlag, Berlin (1996).

32. Watanuki, M., Horie, M., Tsuchiya, K., Obayashi, K., Sasayama, S.: Endothelin-1 inhibition of cardiac ATP-sensitive $\mathrm{K}^{+}$channels via pertussis-toxin-sensitive G-proteins. Cardiovasc. Res. 33, 123-130 (1997).

33. Yanagisawa, M., Kurihara, H., Kimura, S., Tomobe, Y., Kobayashi, M., Mitsui, Y., Yazaki, Y., Goto, K., Masaki, T.: A novel potent vasoconstrictor peptide produced by vascular endothelial cells. Nature 332, 411-415 (1988). 